\title{
Plataformas móveis, gamificação e aprendizagem
}

Rafael Pereira Dubiela, André Luiz Battaiola'

\begin{abstract}
Resumo
Os professores Rafael Dubiela e André Battaiola atuam no Departamento de Design da Universidade Federal do Paraná. Rafael é doutorando do PPGDESIGN/UFPR e atualmente desenvolve tese sobre ensino com base em plataformas móveis e gamificação. André, além de professor doutor na graduação e pós-graduação em Design, desenvolve pesquisa nas áreas de animação, narrativas interativas e design de jogos de computador. Nesta entrevista, respondem questões elaboradas por pesquisadores da Universidad Casa Grande/Equador. [Idiomas disponiveis: português e espanhol].
\end{abstract}

\section{Palavras-chave}

Aprendizagem. Dispositivos móveis. Tecnologias móveis. Tecnologias educacionais.

\section{O que é aprendizagem móvel e como esta se diferencia de outros tipos de aprendizagem?}

RD: É a aplicação de objetos de aprendizagem em dispositivos móveis. A grande diferença é a mobilidade autônoma e o significativo aumento do mercado desses dispositivos todos os anos.

AB: Atualmente, as funcionalidades dos dispositivos móveis (celulares e tablets) têm se aproximado das funcionalidades do computador, em especial, dos notebooks. No entanto, ao contrário dos computadores, celulares e tablets foram criados, na sua origem, para serem portáteis. Esta condição possibilitou aos dispositivos móveis agregarem determinadas funções que os computadores não tinham. Assim, a aprendizagem móvel é aquela que se baseia nos dispositivos móveis e considera as funcionalidades naturais deste tipo de plataforma (questão 2).

\section{Que recursos tecnológicos estão disponíveis para o desenvolvimento de aplicativos para a aprendizagem móvel?}

RD: Os mesmos dos desktops. Apenas se deve observar as limitações dos dispositivos de entrada/inputs (teclado e mouse) e o tamanho reduzido das telas. Uma situação que pode dificultar o desenvolvimento de aplicativos é a variação de tamanhos de telas, que mudam de acordo com marcas e modelos.

AB: A características de mobilidade e de manuseio através de empunhadura por uma ou duas mãos possibilitou que fossem incorporados a estes dispositivos sensores não só para identificação da posição geográfica do dispositivo (GPS), mas também sensores que funcionam como bússolas indicando para onde o dispositivo aponta, bem como a sua inclinação. Estes recursos possibilitam, por exemplo, aplicações de Realidade Aumentada (questão 3). Além disso, estes dispositivos criaram um novo paradigma para o ato de fotografar e/ou filmar ao disponibilizar duas câmeras, uma no lado externo, como em uma câmera normal, onde o foco é um cenário externo ao usuário, e outra do lado interno, voltada para o usuário, ou seja, o foco é o próprio usuário. Esta configuração possibilita uma interação que extrapola a concepção de uma câmera normal, pois o usuário pode estar alocado em uma aplicação em que o usuário filma uma cena e ao mesmo tempo interage visualmente com um observador remoto que analisa aquele cenário filmado.

\footnotetext{
${ }^{1}$ Legenda entrevistados: (RD) Rafael Pereira Dubiela; (AB) André Luiz Battaiola.
} 


\section{Que tipos de recursos didáticos podem ser desenvolvidos para a aprendizagem móvel?}

RD: Curiosamente, os dispositivos móveis entraram nas salas de aulas e no convívio dos alunos (presenciais e no modelo à distância) pela iniciativa deles, não dos educadores. Isso fez com que os educadores, de modo geral, descubram como utilizá-los. Atualmente, vivemos o momento intermediário dessa pesquisa, onde existem muitas formas, mas nenhuma metodologia definida que sirva para várias aplicações.

AB: A portabilidade dos dispositivos móveis os capacita a receber funções que seriam difíceis de serem concebidas considerando um dispositivo estático. Uma dessas funções, por exemplo, é a Realidade Aumentada, que se caracteriza pela incorporação de informações virtuais ao mundo real. Este tipo de aplicação se encaixa perfeitamente a dispositivos móveis, pois o mundo real pode ser associado a aquela que o usuário observa em sua posição virtual. Assim, um museu pode disponibilizar uma aplicação para celulares ou tablets que permita ao espectador do museu apontar o seu dispositivo para um objeto e na tela do dispositivo surgir uma série de informações sobre este objeto. Além disso, a informação da posição atual do dispositivo capacita diferentes aplicações, incluindo as educacionais, a adaptarem determinadas particularidades, por exemplo, um jogo educacional de trânsito pode modificar as condições de uma determinada via de tráfico do jogo para obedecer às condições atmosféricas do local em que o usuário do jogo se encontra.

\section{Como o uso de equipamentos móveis afeta o processo de aprendizagem?}

RD: A aceitação do usuário, a mobilidade, a conexão e a interatividade.

AB: Já foi detectado um comportamento diferenciado nas gerações que se formaram a partir do uso da Internet e da popularização do computador e do celular. Estas gerações caracterizadas como gerações Y e Z apresentam comportamentos de impaciência, pressa na realização de alguma atividade, necessidade de imersão para realizar atividades e habilidades de desenvolver várias tarefas ao mesmo tempo, como, por exemplo, responder a uma mensagem textual no celular, ler um texto no computador e ouvir música. Para os membros desta geração, o ensino tradicional com base na dupla "cuspe-e-giz" é entediante e desmotivador. $\mathrm{O}$ processo educacional pode se beneficiar do uso de objetos de aprendizagem alocados em dispositivos com recursos computacionais, incluindo os dispositivos móveis. Além disso, os dispositivos móveis já são parceiros inseparáveis de uma porção significativa da massa estudantil, logo, se os objetos educacionais estiverem inseridos nestes dispositivos, eles poderão ser facilmente acessados pelos estudantes.

\section{Quais são os fatores que facilitam o uso dos aparelhos móveis no processo de aprendizagem?}

RD: Os dispositivos móveis contam com diversos sensores internos capazes de favorecer a interação com o usuário (detectores de movimento, de inclinação, telas sensíveis, etc). Caso tais dispositivos sejam bem explorados, podem ser excelentes ferramentas pedagógicas.

AB: Os fatores são: a popularização, a facilidade de interação, o fato de serem carregados com os seus usuários (fazem parte de seu cotidiano), de contarem com funções e detectores especiais (posição, inclinação etc), mas, em especial, o fato de eles estarem usualmente conectados à Internet. Esta conexão permite não só suprir o dispositivo com novas aplicações, mas também atualiza-las. Esta capacidade permite equipar e atualizar aplicações educacionais de uma forma barata e simples. Além disso, estas aplicações podem se adaptar facilmente a computação nas nuvens, permitindo que várias informações sejam guardadas em grandes servidores, as quais são acessadas somente em caso de necessidade. 


\section{Por quê o uso de equipamentos móveis nas atividades de aprendizagem está despertando forte} interesse por parte de professores e pesquisadores?

RD: Por que os dispositivos móveis crescem absurdamente, enquanto mercado e utilização.

AB: Os objetos educacionais em ambientes computacionais já são bem conhecidos dos educadores. A partir do momento que os dispositivos móveis se popularizam e expandem seus recursos, não só incorporando funcionalidades dos computadores, mas também adicionando novas, é natural que os educadores comecem a enxergar esta nova plataforma com bastante interesse.

\section{Quais são as tendências no tema da aprendizagem móvel?}

Em princípio, são as mesmas daquelas baseadas em computadores tradicionais (desktop). No entanto, as funcionalidades dos dispositivos móveis extrapolam esta concepção. Assim, uma hipótese passível de ser cogitada é que, em vários aspectos associados aos dispositivos móveis, a tecnologia se encontra em um estado de transição. Este tipo de transição pode ser comparado a aquelas associadas a outras transições, como, por exemplo, da pintura para a câmera fotográfica, do teatro para o cinema, do slide em película para o slide no computador etc, ou seja, por um tempo, os educadores irão encarar os dispositivos móveis como um computador tradicional, eles enxergarão apenas a sua capacidade de processamento e de comunicação com a Internet, no entanto, com o tempo começarão a considerar suas outras funcionalidades (detecção de posição, de movimento e de inclinação, facilidade de manuseio e porte, popularização etc). Neste momento, o que se antevê são aplicações que irão conjugar de forma abrangente e eficiente os recursos dos dispositivos móveis com técnicas e processos educacionais. 


\section{Mobile platforms, gamification and learning}

\begin{abstract}
Rafael Dubiela and André Battaiola from the Federal University of Paraná/Brazil (UFPR) answer questions drawn up by researchers at the University Casagrande - UCG/ Ecuador. Those questions refer to the role of mobile platforms in learning processes and their reasoning shed light to the discussions about available resources, the differences between traditional learning and the ones based on such devices, the impact of mobile devices on learning and the foreseen future that characterizes this topic. [Available languages: Portuguese and Spanish].
\end{abstract}

\section{Keywords}

Learning. Handheld computer. Mobile Technologies. Educational technologies.

Rafael é Bacharel em Desenho Industrial - UFPR, Mestre em Design - UFPR, Doutorando em Design - UFPR. Professor Assistente - UFPR, Coordenador dos Cursos de Tecnologia em Jogos Digitais - CTP. rafaeldubiela@gmail.com

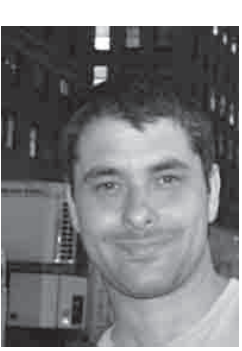

André é Bacharel em Física - USP, Mestre em Engenharia Elétrica USP, Doutor em Engenharia Elétrica - USP, Estágio Pós-Doutoral no SSEC/Universidade de Wisconsin/ EUA. Professor Associado IV - UFPR. ufpr.design.profe.albattaiola@gmail. com

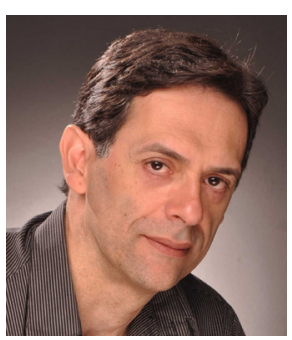

Como citar este documento:

DUBIELA, R. P.; BATTAIOLA, A. L. Plataformas móveis, gamificação e aprendizagem. AtoZ: novas práticas em informação e conhecimento, Curitiba, v. 2, n. 2, p. 82-85, jul./dez. 2013. Disponivel em: <http://www.atoz.ufpr.br>. Acesso em: . Entrevista.

\section{Agradecimentos}

A equipe editorial agradece aos docentes-pesquisadores da Facultad de Ecología Humana, Educación y Desarrollo da Universidad Casa Grande/Equador, pela elaboração das perguntas. 